\title{
The Historic Orientation of the Development of Media Technology of Social Development of Mankind in Modern Times
}

\author{
Yan-Ran DING \\ Doctor, Business School of Hohai University, Nanjing Povince, China \\ Email: dddhxx@163.com514643065@qq.com
}

Key words: Man In Modern Times, Social Development, Media Technology, Historic Orientation

\begin{abstract}
Variegated world under traditional polygon prism, it is the driving force of Social Development of Mankind in Modern Times, which is also the historic footprint it carries through, media is spurring the future of globalization with its digitalization. It conceals the original meaning of life and man's fate and indicates where mankind is heading to. Through the media, People's interwoven concepts, ideological clash, emotional exchange and objective acknowledgement, so we can march towards the same orientation, aim at the same goal, share the same world and bask in the pleasantly warm sun.
\end{abstract}

\section{Traditional Polygon Prism}

The world forged by media technology is likened to a variegated world perceived by a child or an innocent scientist through his traditional polygon prism.

\section{Variegated World under Traditional Polygon Prism}

The variegated mirror image seen through polygon prism cover all figures, texts, sounds, images and other perceptible factors and forms covering books, magazines, newspaper, adverts, phone, broadcasting, motion pictures, animation, digital, online culture, cloud computer in modern and future times and big data. A chromatic world is both the original image of the world and mirror image of the more outstanding and queer traditional polygon prism. Rather than a visual camera shooting or being used for appreciation, it conceals the original meaning of life and man's fate and indicates where mankind is heading to.

People vary in their respective visual and audio channels for interwoven concepts, ideological clash, emotional exchange and objective acknowledgement, but they can reach consensus via comparison, identification, sifting and absorbing with the same visual and audio organs and the same intelligence, so we can march towards the same orientation, aim at the same goal, share the same world and bask in the pleasantly warm sun.

An individual can get connected to tens of thousands of households with the help of books, magazines, phones, broadcasting, television and advertisement while animation, digitalization and networking enable tens of thousands of households play games, engage in talks and entertain themselves under the same roof. When cloud computing and big data connects the future, it links mankind and the whole world into a family. In actuality, such a prospect is by no means the riotous mirror image via traditional polygon prism, it is a true image reflected by the polygon by the genuine outstanding world after we transcend the limitation by nude eyes. After we accurately measure image formation and intersection channel of each frame of mirror image, we can restore the true prospect of the whole. it is where the value and function of traditional polygon prism with variegated mirror images lies.

\section{Printing Era}

Calls of animals are coarse while languages of mankind are delicate, but emergence of words brings about huge changes in the signal realm. Books show up and a visible signal system that can be preserved emerges. When it proliferates via printing technologies and gets promoted to all over the 
world, fertility of all creatures is outshone. In particular, when breed is no longer an organism per se but wisdom with infinite creativity, the world with gestation of printing technology is to be printed. So life-changing radical changes in this blue planet are nothing but inevitable.

Magazines can be deemed as spiritual fast food position in shelves following categories. They are likened to a riot of colorful fast-food slice while professional academic magazines are compared to compressed biscuits when one slice amounts to a bowl of rice. But newspaper in newsstand belittles them all in propagation speed and range as the paper within touch is timely though it fails to register a profound memory. It helps all literate people chime with the era. Other than printing the world, it is printing man who shadows previous man in generality.

\section{Phone and Broadcasting}

Since 1875, a young man from Scotland, had accidentally invented the phone after he came across that coil can produce sound, current circulates cabinet phone began to be widely applied in hotels, telephone booths and private hoses 17 years later. Today, people can talk with people living at the other end of the earth via picture-phone as if they were by their side at home. Videophone via common phone brings two people living far apart closer and helps them engage in direct talk. Then what's the point of bitter quarrel and estrangement among people?

By extending phone or videophone, that a man or team expresses views to many forms communication. It is a more extensive bond between man. Though communication has become history due to people's rights of independent selection, yet it used to add momentum to connect people in its historic course of calling the public and cohesion of people's mind.

\section{Advertising on Movie and TV}

With extension of computers in movie and TV and software development, 3-D digital image technology transcends limitation of shooting and mends its insufficiencies. Animation and digital exhibition establishes the high-speed tunnel of the virtual and real world via visual images. By connecting images to hardware, it derives multiple forms of acoustic images. With its 360-degree ring screen system, it encircles the audience and is installed with 3-D images before creating profound immersion experience. Animation can demonstrate umpteen display board information via a liquid crystal display. With dynamic image content and interactive model, it can demonstrate vivid performance. It has been widely applied to digital city, renovation of historic site, virtual travel, project rehearsal, industrial simulation and so forth.

Advertisement gets its evil reputation due to its coerciveness such as coercive registration, pop-up of pages for advertisement, which is repulsive. It compels the advertising industry to restrain itself, makes it benefit from communication culture, civilization and mutual communication and spurs joint understanding, rights to know and interests sharing of mankind.

\section{Network Culture}

With network information technology as the basis, it forms cultural activity, product and concept in the cyberspace and is the extension and diversified exhibition of social culture in the reality. Its unique cultural characteristics, cultural products and value concepts also take shape. A synthesis of emerging technologies and cultural content, it incorporates network spirits with matter creation as the basis.

As network is circulated all over the world, local culture can be assimilated, fused and derived into cosmopolitan culture other than its being widely acknowledged on-line so that people's life and civilization can be delivered and clustered through online overflowing. Examples include Uncle Bus from Hong Kong, Gangnan Style by PSY, a singer from South Korea and so on.

Network culture in its broad sense also refers to culture of mankind in the internet era. It is the extension and diversified exhibition of traditional culture and morality of mankind and spurs harmonious development of human society. Particularly speaking, its function of clustering popular will helps the masses give voice to their own ideas, vision and thoughts via network so that a 
convenient tunnel of collecting information and addressing information can be provided to the exchange platform.

\section{Future of Digitalization}

It is a process of transferring continuous and changeable signals to separable units, converting complicated information to measurable data and numbers and establishing a digital model followed by unified disposal by computers. Shen Nong in the 1940s verified sampling theorem that rooted foundation for digital technology. Digitalization and networking just take pace. The $21^{\text {st }}$ century witnesses that all analog media would gradually be supplanted by digital media and that TV, broadcasting, phone and internet would be fused into a whole. Online publishing will replace paper magazines, books would be digitalized, e-business will become the main means of commerce, the bulk of commodity trade will be carried out through network and automobiles and electric appliances can be remotely controlled, maintained and fixed.

Fees for wireless internet will be dwindling to null. People will rid reliance of time and site of going on line, making network stretch to all corners in the earth and connect all people to the big family of the world. Different places will see their development gap shrinking and a homogenous culture and language universal to the world will take form. Political and geological boundary will grow vaguer and the concept of global village and global home in its genuine sense will come true. The $21^{\text {st }}$ century marks a new century when the world as a whole is united.

\section{Historic Orientation of Media}

The most valuable contribution of history is its footprint that helps late-comers judge orientation and determine where the future is extending.

\section{Review to the Past}

By reviewing to the past, media went through the evolution from information delivery and media control by people to media's dominance over man so that media has surged into the 'fourth power' in modern times.

In 1890, Tarde who published Rules of Imitation became the founder of imitation theory under the category of social psychology. He reckoned that all social things 'were inventions or simulations' and that media accomplished the simulation.

As a famous philosopher and educator of pragmatism, Deway held that communication was a major instrument to reform the society and new communication technologies would lead to reconstruction of the social value system.

In the chapter of Communication in his book entitled Social Organization published in 1909, Cooley, an American educator, profoundly elaborated the concept, significance, psychological function of communication as well as printing media, modern society and formation of consensus. The famous Lippman analyzed nature of news and its election and proposed the concept of 'analog environment' and 'dual nature of environment' in such treatises as Freedom and News, Consensus and so forth. After the 1920s, Harold Dwight Lasswell, Lewin, Hovland and Lazarsfeld are taken as four founders of communication science due to their study and academic activities on communication. 1

History is indicative that we should not be dithering or hesitating before taking the road of hope to the Garden of Eden.

\section{Media is Used to Call for Gathering}

Media per se is by no means a road but a wind vane and horn on the path of man's civilization. So media is a discussion, public opinion and influence to distinguish orientation and it is 'a capacity of cultural performers to sway other people's behaviors in the way they fancy'. 2 In essence, influence is also a control power that is reflected in the effect of controlling cognition, mindset and behaviors 
of receivers of influence. It is realized via information communication process and is established on the ground of attention and contact by receivers. Therefore, the influence of media consists of two parts namely 'attraction of attention plus changes of goals' that thus carries dual nature respectively, one, attributes of physical technologies and two, dynamic nature of the society. In particular, the later can only be feasible with public selection and backup.

But as far as media, notably mass media, goes, media is akin to horn, alarm, harbinger of dawn or morning bell that is an initiative alarm and appeal of the public rather than a passive affiliation. Special gathering or public get-together such as meeting, parties, lantern festival, concerts and the like can't do without media. Where do those gathering lead to? The result remains the same as being gathering and get-together despite variance in purpose, intention or orientation. For the earth with a population of 7 billion, media, as a natural medium connecting events and man and between man, displays its effect in a unified rather than divided manner, which is the highest significance of media on people who take a gregarious life. Media is forever calling for gathering and will never cease to call for mankind to the eventual global unity.

\section{Dialogue Connects Us All}

In the story on the Three Kingdoms, Liu Bei was beset by difficulties by officers in East Wu Kingdom when he went and sought refuse with the kingdom. Zhuge Liang, his military counselor, argued heatedly with them and convinced Sun Quan to fight against Cao Cao together to guarantee their survival. Foreign ministers also serve the role as professional persuaders to defend their own countries. The Bush administration's assault to Iraq 'installed' hundreds of correspondents from different countries to the military army, marking the first time that news media was used as a weapon to the war. The power of 'consensus' or public words can be thus seen. The huge dominant role of mass media on public consensus, notably its far-reading impact on political consensus, can be thus indicated. Political consensus would sway people's behaviors that would be converted to gigantic physical power when it is welded in an organized way. So Theodor White, a famous scholar from the US, used to put it, 'in America, no major legislation in the Congress, foreign risks, diplomatic activities or major social reform can be successful unless the news has got public ideology prepared.' In today's world, dialogue connects us all. International relations are, first of all, hinged on what we say on the international stage that then would determine what people do after that.

\section{Hedge and Attraction of People's Mind}

When we make comments on nature of a person, we judge it based on 'his heart'. What is it? And what is 'heart of mankind'? Ernst Cassirer, founder of cultural philosophy and a German philosopher, proposed in his masterwork entitled An Essay on Man that man was 'a creature of signals', culture was the form of signals and the essence of human activities was a 'symbolic' or 'symbolic' activity 3. Man emerged due to natural evolvement but the evolvement does not incur the connotation that put man to what he is today in the form of man. Advanced creature is by no means man and man is not advanced by the same token. Physique is not a standard telling man apart from animals and walking straight does not mean man is more dignified than other forms of life. Man is different from animals in his 'soul' or 'spirit' and wisdom and 'man's heart' incurred by it. The connotation when 'man's heart' is interpreted is his emotional capacity. For human being who takes a collective life, that man is good or bad is embodied in 'hatred' and 'love' and its role on the whole group is reflected in its 'hedge' or 'cohesion'.

It is a long process of evolvement and progress that is marked by struggles, wars, destruction and eradication. In the evolution and sublimation of rationality and 'man's heart', it can be a gradually updated process awash with forgiveness, reconciliation, collaboration and mutual win. The most spectacular designing of the world by God is that all acting forces have equal adverse effect, which give them perpetual vibrancy and immortal life. Only one choice is left for parties involved (i.e. mankind): when strife can bring destruction to its survival, people would go to great length to 
transcend the hedge and head towards cohesion at least for the benefit of their survival and hence the world in peril would head towards congruity.'

\section{From Today to the Future}

For the moment, the media technology is heading towards two ways: first, by bonding with broadband network, it enables multimedia to such sectors as scientific research designing, company management, office automation, remote education, remote medication, retrieval and consultancy, cultural entertainment, automatic control and so forth; second, with component-oriented, smart and imbedded multimedia terminals, multimedia performance of computer system per se is improved and smart home appliances are developed. Technological innovation helps improve performance of servers, routers, transverter and other network devices while user-end CPU, storage, graphic car and other hardware capacity would be extended without precedence so that network appliers would more initiatively enter the online virtual world, more media computers would form more completed a synergic working environment, the barrier of space and time would be wiped out and more consummate information can be provided to mankind.

Such services belong to the present. It can be taken as dawn rather than dusk when progress made to constantly improve man's instrument and means of survival is validly guaranteed, for the setting sun is more glorious than the dawn at times. Concretely put, when media technology or all sciences have innumerable great achievements and are within easy touch and when a growing number of countries, nationalities or a small dictator in any part of the world can easily own core technologies that would exterminate the world, progress of any technologies would signify the advert of murkiness. We can't hold back the sinking sun but we should carry the belief that cohesion of people is way easier than nuclear fusion.

\section{References}

[1] Zhang Huimei, Academic Journal in Xiangtan University (philosophy and social science edition), 2003, 27 (4):19-22.

[2]. Wang Yin, Study on Relation between Influence of Media and Attention by Targets, Northeast Normal University, 2012

[3]. [Germany] Ernst Cassirer, An Essay on Man 